\title{
Idiopathic subglottic stenosis: a review
}

\author{
Carlos Aravena ${ }^{1,2}$, Francisco A. Almeida ${ }^{1}$, Sanjay Mukhopadhyay ${ }^{3}$, Subha Ghosh ${ }^{4}$, Robert R. Lorenz ${ }^{5}$, \\ Sudish C. Murthy ${ }^{6}$, Atul C. Mehta ${ }^{1}$
}

${ }^{1}$ Department of Pulmonary Medicine, Respiratory Institute, Cleveland Clinic, Cleveland, OH, USA; ${ }^{2}$ Department of Respiratory Diseases, Faculty of Medicine, Pontificia Universidad Católica de Chile, Santiago, Chile; ${ }^{3}$ Department of Pathology, Robert J. Tomsich Pathology and Laboratory Medicine Institute, ${ }^{4}$ Department of Diagnostic Radiology, ${ }^{5}$ Head and Neck Institute, ${ }^{6}$ Department of Thoracic and Cardiovascular Surgery, Heart and Vascular Institute, Cleveland Clinic, Cleveland, OH, USA

Contributions: (I) Conception and design: C Aravena, AC Mehta; (II) Administrative support: All authors; (III) Provision of study materials or patients: All authors; (IV) Collection and assembly of data: C Aravena, AC Mehta; (V) Data analysis and interpretation: All authors; (VI) Manuscript writing: All authors; (VII) Final approval of manuscript: All authors.

Correspondence to: Atul C. Mehta, MD, FCCP. Lerner College of Medicine, Department of Pulmonary Medicine, Respiratory Institute, Cleveland Clinic, 9500 Euclid Ave, A-90, Cleveland, OH 44195, USA. Email: mehtaa1@ccf.org.

\begin{abstract}
Idiopathic subglottic stenosis (iSGS) is a fibrotic disease of unclear etiology that produces obstruction of the central airway in the anatomic region under the glottis. The diagnosis of this entity is difficult, usually delayed and confounded with other common respiratory diseases. No apparent etiology is identified even after a comprehensive workup that includes a complete history, physical examination, pulmonary function testing, auto-antibodies, imaging studies, and endoscopic procedures. This approach, however, helps to exclude other conditions such as granulomatosis with polyangiitis (GPA). It is also helpful to characterize the lesion and outline management strategies. Therapeutic endoscopic procedures and surgery are the most common management modalities, but medical therapy can also play a significant role in preventing or delaying recurrence. In this review, we describe the morphology, pathophysiology, clinical presentation, evaluation, management, and prognosis of iSGS.
\end{abstract}

Keywords: Idiopathic subglottic stenosis (iSGS); subglottic stenosis (SGS); laryngostenosis; granulomatosis with polyangiitis (GPA); tracheal stenosis

Submitted Aug 01, 2019. Accepted for publication Nov 14, 2019.

doi: $10.21037 /$ jtd.2019.11.43

View this article at: http://dx.doi.org/10.21037/jtd.2019.11.43

\section{Introduction}

Subglottic stenosis (SGS) is the obstruction of the central airway in the region bounded superiorly by a plane below the glottis and inferiorly by the first two tracheal rings $(1,2)$.

When no cause is evident after a comprehensive evaluation, this disease process is referred to as idiopathic subglottic stenosis (iSGS), a rare fibrotic disease of unclear etiology and pathobiology. Its estimated incidence is 1:400,000 and it almost exclusively affects women between the third and fifth decades of life (3-5) (Figure 1).

iSGS is a relatively new entity, the first cases being described by Brandenburg in 1972 (6). Since then, only anecdotal reports and small case series have been published.
The pathogenesis of this disease remains a mystery, and its diagnosis and management a clinical challenge $(4,5,7,8)$.

Consequently, iSGS is considered as an "orphan" respiratory disease despite its potential for lethal outcomes (9).

In this article, we discuss possible etiologies, clinical and pathologic characteristics, and management of iSGS. The purpose of this review is educational and is oriented principally towards pulmonary physicians and interventional pulmonologists.

\section{Etiology}

Several etiologies have been proposed in the literature for subglottic stenosis, the most common being trauma 


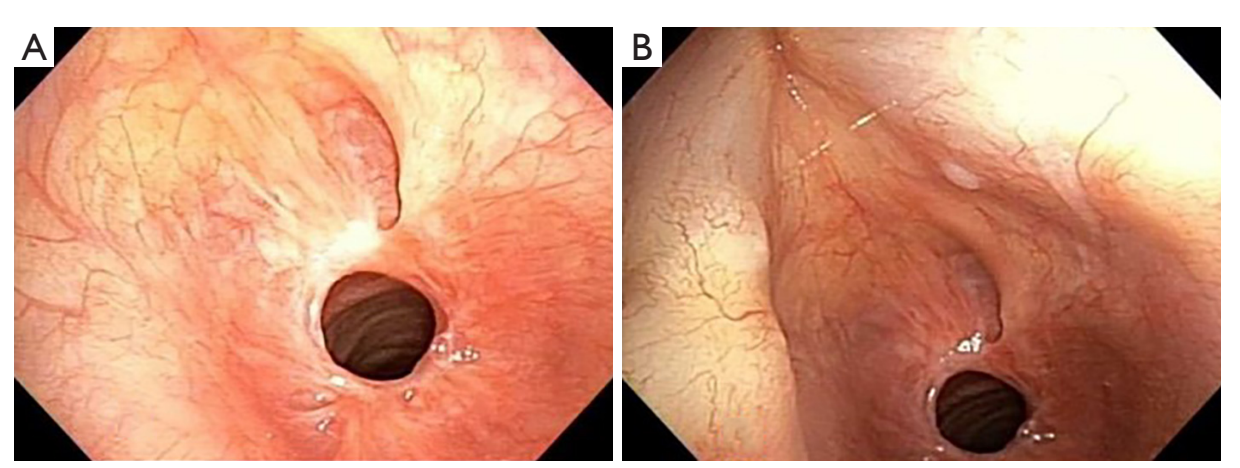

Figure 1 Idiopathic Subglottic Stenosis in a 55-year-old female. Note concentric web-like nature of the lesion.

Table 1 Etiology of central airway stenosis $(5,10)$

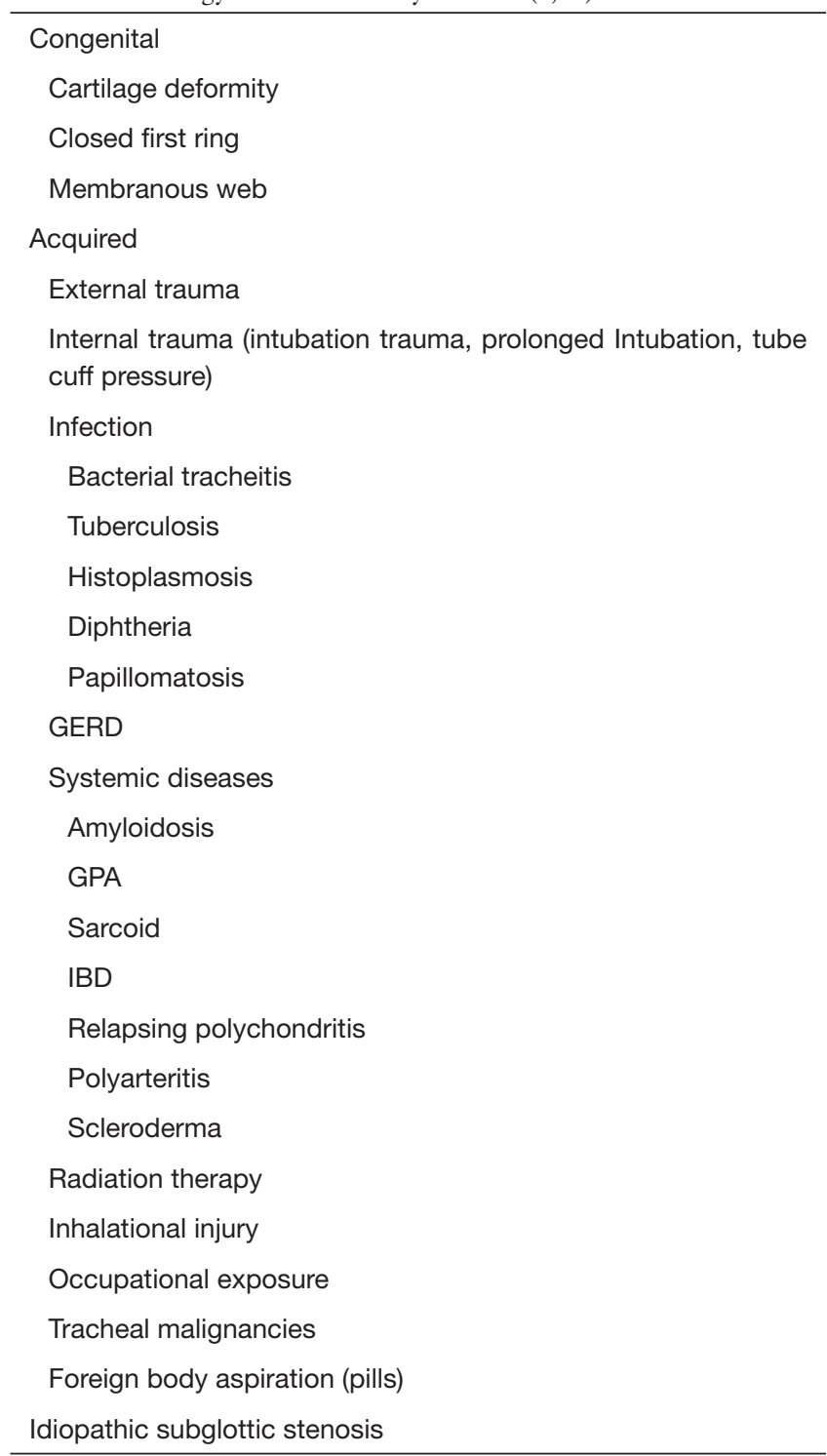

GRED, gastroesophageal reflux disorder; GPA, granulomatosis with polyangiitis; IBD, inflammatory bowel disease. secondary to prolonged intubation, excessive endotracheal tube cuff pressure, and tracheostomy. Less frequent causes include infection, gastroesophageal reflux disorder (GERD), systemic diseases, radiation therapy, inhalational injury, occupational exposures, inflammatory bowel disease (IBD), primary and secondary tracheal malignancies, and congenital conditions (Table 1). It is essential to take these possibilities into consideration in order to identify mimics of iSGS.

Traumatic intubation, as described above is the most common cause of laryngotracheal stenosis. High-pressure cuffs or prolonged intubation may cause mucosal damage in the form of inflammation, ulceration and cartilage breakdown, which may lead to stenosis involving the upper or mid-trachea (Figure 2). Repeated intubations, the presence of a nasogastric tube, and the size of endotracheal tubes are the mechanical risk factors for this complication. While susceptibility to infection, poor perfusion, and systemic comorbidities are patient-related risk factors (11).

Despite its causative role is controversial, GERD may contribute to the development of SGS given that it seems to be more prevalent in patients with this condition. Presumably, mucosal damage and inflammation caused by gastric acid lead to the development of tissue fibrosis. In 2011, Blumin et al. reported 22 patients with iSGS, 59\% of which had pepsin in their laryngeal or tracheal mucosa. The latter were all women with a mean age of 53 years (range, $32-82$ years). Of these, $54 \%$ had a history of GERD, and $76 \%$ had laryngopharyngeal reflux (12).

Stenosis caused by granulomatosis with polyangiitis (GPA) occurs in $10 \%$ to $23 \%$ of patients with this condition (13-15).

In 1996, Langford and colleagues reported 43 patients with GPA and SGS and found an equal incidence in both genders (13). The median age at the time of diagnosis was 
26 , though symptoms were more frequently present before 20 years of age. At presentation, half of the patients had no evidence of active disease affecting other organs $(13,16)$.

Patients with GPA who are younger than 20 years of age appear to have a higher incidence of SGS $(11,14,17)$.

Interestingly, even though cytoplasmic staining pattern of the antineutrophil cytoplasmic antibody (c-ANCA) is positive in only $57 \%$ of these subjects at presentation, up to $87 \%$ have a positive c-ANCA at some point during the course of their disease $(13,18)$. Subglottic biopsies are often unrevealing $(13,19-21)$.

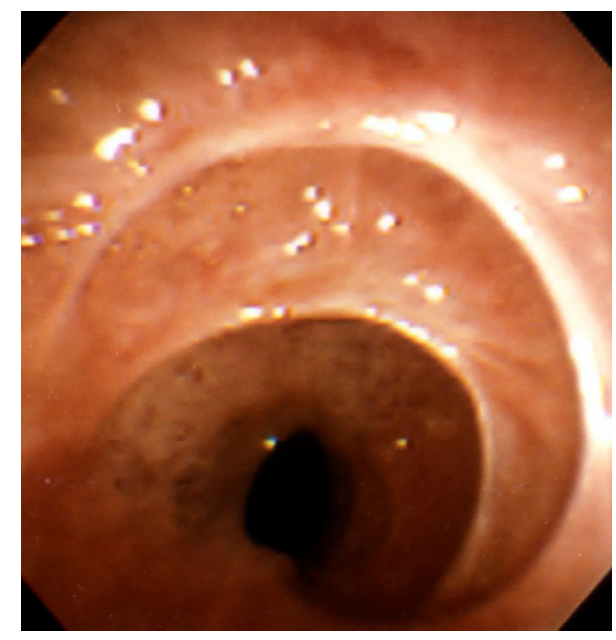

Figure 2 Post intubation stenosis from the high cuff pressure injury.
In a retrospective study comparing GPA with SGS and iSGS, Taylor et al. highlighted that in the iSGS group, vast majority of patients were women and had worse Myer-Cotton stenosis grade (vide-infra). In the GPA group, $40 \%$ were men and were more likely to undergo a tracheostomy (21) (Figure 3A,B).

Sarcoidosis is a multi-systemic granulomatous disease of unknown cause that involves the respiratory system in more than $90 \%$ of cases (22). Airway involvement has been described in approximately two-thirds of patients, and its frequency usually increases when parenchymal lung disease progresses (23). Sarcoidosis airway disease is associated with augmented morbidity and mortality (24). Lobar, segmental and subsegmental airways are more frequently involved than central airways (23). Subglottic stenosis due to sarcoidosis has been described only in a few anecdotal cases (25).

Respiratory manifestations of IBD are rare and usually subclinical $(26,27)$. Pulmonary involvement with ulcerative colitis (UC) was reported in $0.21 \%$ of 1,400 subjects in one study $(26,28)$. Among these, airway involvement occurred in $41 \%$ and presented as chronic bronchitis, bronchiectasis, subglottic inflammation or tracheal or bronchial stenosis. Parenchymal lung abnormalities were present in $27 \%$, while pleural involvement was seen in $17 \%$ (28). Myocarditis and pericarditis were reported in $15 \%$ of patients with intrathoracic compromise (28). Respiratory involvement in Crohn's disease (CD) is even more unusual (29). Accordingly, glottic and subglottic stenosis has been more commonly described in UC than CD (26).
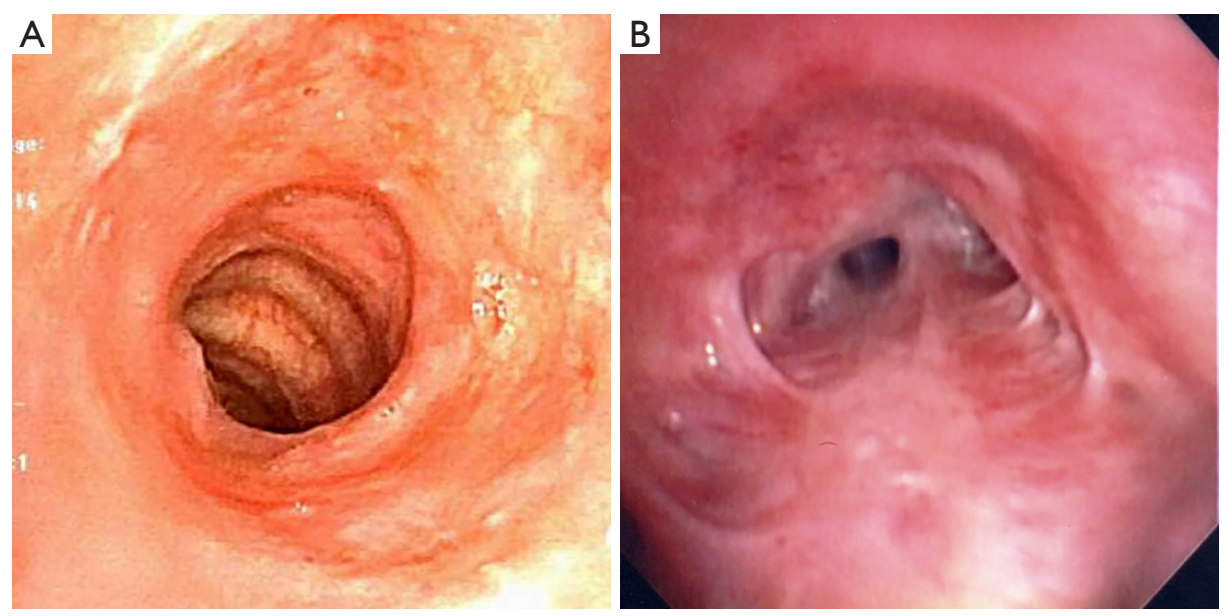

Figure 3 Granulomatosis with polyangiitis related airway stenosis. (A) Subglottic stenosis in a patient with GPA; (B) Tracheal stenosis related to GPA. GPA, granulomatosis with polyangiitis. 


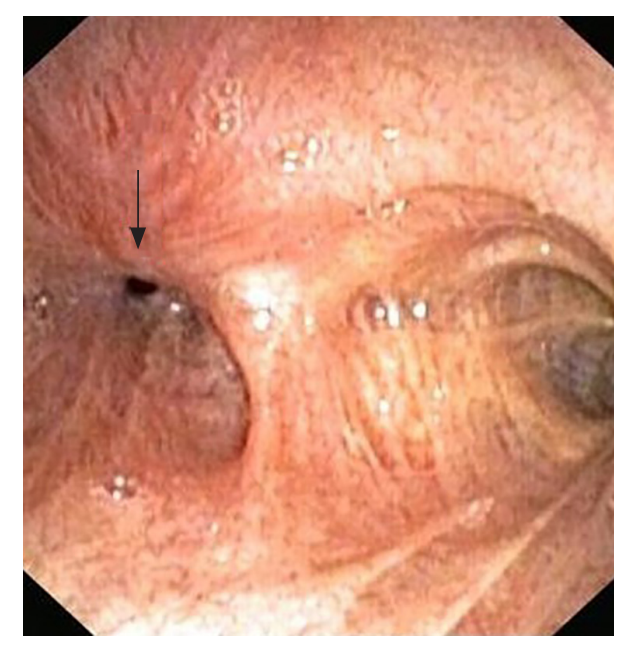

Figure 4 Truncus medius anastomosis following a potassium pill aspiration.

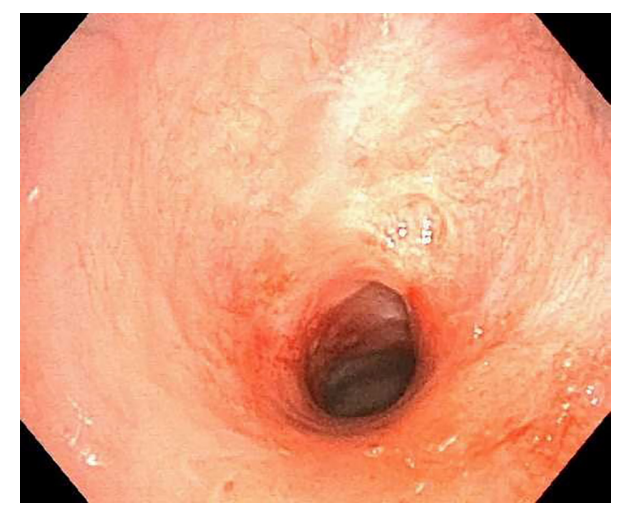

Figure 5 Idiopathic subglottic stenosis longer than $1 \mathrm{~cm}$ in length.

Anthracosis and exposure to silica have rarely been reported as a cause of airway stenosis and should be suspected with thorough history taking (30).

Another cause of airway stenosis that should be taken into consideration is foreign body aspiration, especially the pills that may dissolve in the airways (31). It may promote significant inflammation and potentially lead to airway stenosis. This could be a severe and potentially fatal problem that occurs mainly in the sixth or seventh decade of life due to the failure of protective airway mechanisms (31). Iron, potassium chloride, alendronate, nortriptyline, and pomegranate supplements are the pills that have been reported to cause this complication (32) (Figure 4).

Congenital subglottic stenosis is a rare condition seen in pediatric patients. The diagnosis is clinical and endoscopic.

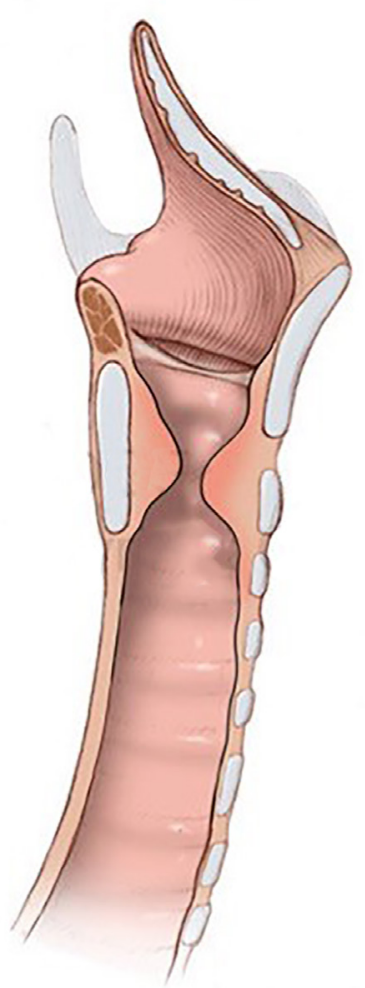

Figure 6 Subglottic stenosis, sagittal view.

Only a few adult cases have been described in the medical literature $(33,34)$.

In less than $5 \%$ of cases, no apparent etiology is identified, establishing the diagnosis of iSGS (35-37). Thus, the determination of iSGS is based on the exclusion of etiologies listed above $(5,38,39)$.

\section{Pathophysiology}

Analyzing the anatomical aspects of iSGS, it is recognized that most lesions begin at the cricoid cartilage, with the point of maximal stenosis located between its upper edge and the first tracheal ring (5).

The stenosis is usually circumferential but may be eccentric. The average length of the stenosed segment is typically from 1 to $3 \mathrm{~cm}(5,38)$ (Figures 5,6).

Histopathology of these lesions usually reveals dense fibrosis of the keloidal type with occasionally interspersed fibroblasts. Inflammation tends to be sparse. There is often dilatation of minor salivary glands and ducts. The overlying epithelium frequently shows squamous metaplasia. 

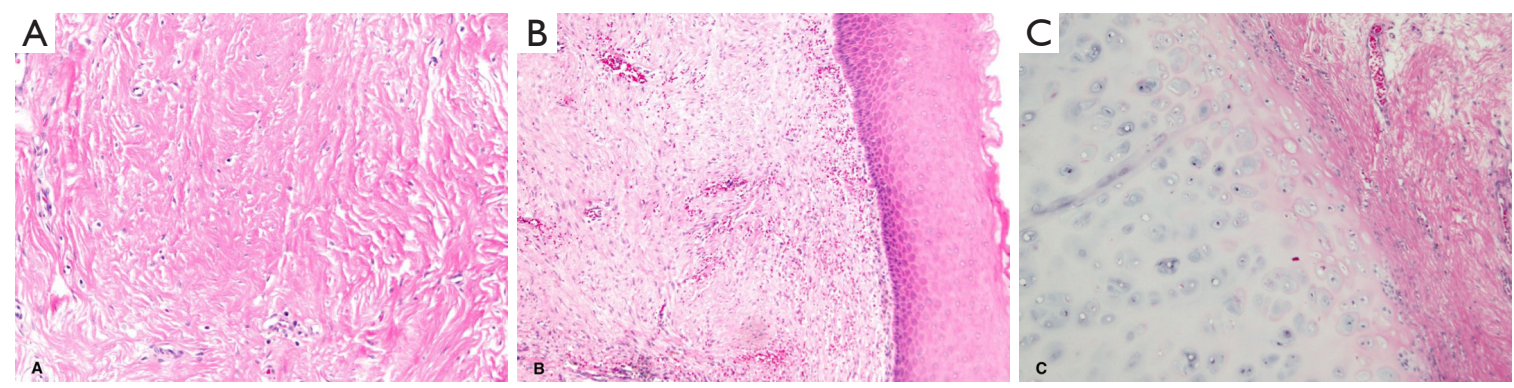

Figure 7 Histologically, iSGS is characterized by dense, keloid-like fibrosis (A). The overlying epithelium often shows squamous metaplasia (B). Cartilage is histologically normal (C). iSGS, idiopathic subglottic stenosis.

Ulceration of the epithelium may occur, with the formation of granulation tissue. Cartilaginous rings are usually histologically normal (39) (Figure 7).

As stated earlier, the pathogenesis of iSGS is unclear, but several hypotheses exist. The vast majority of patients are women, prompting the theory that estrogen influences the development of stenosis $(1,5)$. Interestingly, there is no evidence of overexpression of estrogen or progesterone receptors in the cells involved in the disease process $(1,12)$.

Another hypothesis postulates that trauma from repeated cough may lead to "telescoping" of the first tracheal ring into the ring of the cricoid cartilage, resulting in mechanical injury, ischemia, and anomalous wound repair, possibly potentiated by an abnormal response to estrogen, explaining the female predominance of this disease (37).

The role of GERD resulting in irritation and subsequent stenosis is a hypothesis supported by multiple observational studies reporting a higher incidence of GERD among this patient population compared with the general population (12).

Besides, animal and human studies have shown high levels of pepsin in the subglottic scar and larynges from patients with iSGS. Interestingly, the findings do not correlate with the presence of GERD diagnosed by $\mathrm{pH}$-metry, suggesting that the standard test may be an inadequate predictor of GERD in patients with iSGS (12).

However, there is limited evidence to suggest GERD as a causative agent, and the etiology of this disease remains to be proven the link provides some justification for recommending anti-reflux measures in the management of iSGS $(1,5,12)$.

\section{Diagnosis}

Patients with iSGS are almost exclusively Caucasian women $(3-5,40)$. The typical age range is 30 to 60 years $(5)$. The most common symptoms are exertional dyspnea, stridor, chronic cough, and wheezing, with a mean duration before diagnosis ranging from 19 months to 4 years $(4,7)$.

The majority of these symptoms are reported late in the course of the disease when the stenosis reaches more than $50 \%$ of the airway diameter $(9,38)$.

Therefore, a significant proportion of patients who have central airway stenosis but no risk factors, the diagnosis is overlooked, leading to erroneously diagnoses of other respiratory diseases (9). It is not surprising that as many as one-third of patients are misdiagnosed with either asthma or COPD (3-5).

In addition to a thorough history and physical examination, the evaluation should include serologic testing for antineutrophil cytoplasmic antibodies (ANCA), angiotensin-converting enzyme levels (ACE), pulmonary function tests, computerized tomography (CT) and endoscopic examination.

The flow-volume loop reveals fixed upper airway obstruction when patients develop severe stenosis. This observation is also associated with a reduction in maximal voluntary ventilation despite preserved muscle strength and patient effort (41) (Figure 8).

A chest $\mathrm{X}$-ray is of limited value in the diagnosis of iSGS. Chest and neck CT with 3D reconstruction or virtual bronchoscopy $(\mathrm{VB})$ provides invaluable information in the diagnosis and management of iSGS $(5,8)$ (Figure $9 A, B, C, D)$.

High-resolution CT using multi-row detectors allows three-dimensional reconstruction along with VB that helps define the characteristics and type of stenosis (concentric, complex, hourglass, etc.). The sensitivity of VB for tracheal stenosis is $94-97 \%$, and the specificity is $100 \%$ when compared with intra-operative findings (42).

Dynamic expiratory CT may allow the identification of airway collapse due to tracheomalacia which is occasionally 


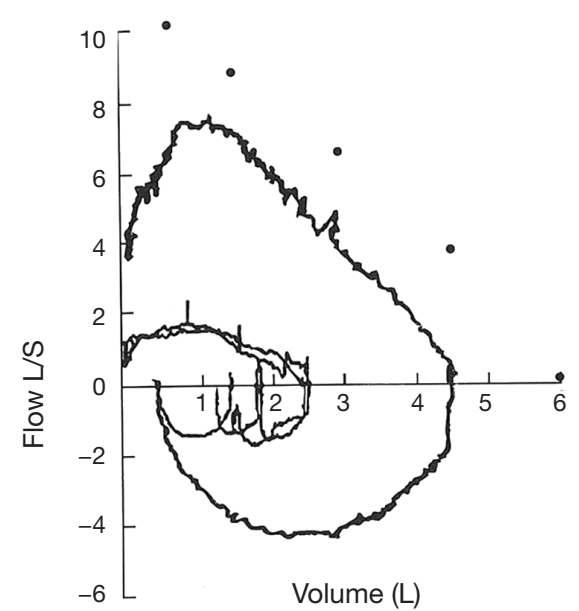

Figure 8 Flow-volume loop is demonstrating fixed upper airway obstruction [Inner loop]. Dots denote predicted values. Outer loop depicts near normalization of the flow rates following appropriate treatment.

associated with iSGS (8).

Multiplanar reconstruction can also provide equivalent information in the workup of these patients.

Endoscopic (laryngoscopy or bronchoscopy) evaluation is the gold standard in the diagnosis of iSGS and is essential to plan management strategies. Flexible endoscopic examination determines fundamental characteristics of iSGS, such as location, extent, and complexity. A concentric web-like stricture measuring less than $1 \mathrm{~cm}$ in length without the involvement of the cartilage is referred to as a "simple" stricture while a stricture associated with structural defects is considered "complex".

There are two widely accepted grading systems for classifying central airway stenosis used as prognosis predictors. The Myer-Cotton system classifies the grade of stenosis into four groups, and the McCaffrey system has four stages related to the location and length of the lesion $(2,43)$ (Tables 2,3). The Myer-Cotton system is based on the reduction of the cross-sectional area for mature, firm and circumferential lesions where an endotracheal tube can be used to determine the size of the obstructed airway. Its main limitations are the lack of consideration of the length or complexity of the lesions. Although it is considered the gold standard for staging in pediatric patients, it has not been correlated with outcomes in adults (43). Based on a study involving 72 cases with laryngotracheal stenosis, the only statistically significant factors in the McCaffrey system were the site and the diameter of stenosis. The system, however, only predicts the probability of successful decannulation (2).

At this stage, the endoscopic examination is warranted. It should be noted that in cases of severe stenosis, the flexible endoscopic examination can further obstruct the airway and add to respiratory distress and its consequences. Among patients with preexisting respiratory distress, proceeding directly to rigid endoscopy might be advisable $(2,5,43)$. In our experience, most of the patients with a high clinical probability of subglottic stenosis do well under general anesthesia with a laryngeal mask airway in place; while at the other extreme, severely symptomatic patients may require awake tracheostomy prior to therapeutic interventions. Endoscopic intervention, if indicated, can be accomplished at the same time as the diagnostic procedure.

Radial probe endobronchial ultrasound with a balloon can help determine the thickness of the lamina propria of the tracheal mucosa, the extent, and complexity of the stenosis and the structure of cartilaginous rings. The latter is helpful in differentiating iSGS from conditions such as relapsing polychondritis (44).

\section{Treatment}

Optimal management of iSGS requires the collaboration and availability of a multidisciplinary team, including interventional pulmonology, otolaryngology, thoracic surgery, and anesthesiology. There is a lack of data to support medical therapy alone for symptomatic iSGS. It is partially based on the very low prevalence of the disease lending few opportunities for randomized trials. Among the alternatives described above, aggressive treatment of GERD is the only reasonably accepted therapy that is supported by observational studies. When anti-reflux measures are combined with oral trimethoprim-sulfamethoxazole and inhaled corticosteroids, a possible reduction in the rate of recurrence has been noted. However, this observation needs prospective studies for confirmation $(3,12)$.

Patients with "simple" concentric web-like stenosis not involving cartilage can be considered for therapeutic endoscopy while those with complex lesions require surgical correction.

\section{Therapeutic endoscopy (laryngoscopy or tracheoscopy/ bronchoscopy)}

Endoscopy has the advantage of being a less invasive procedure that can be performed in the outpatient setting. 


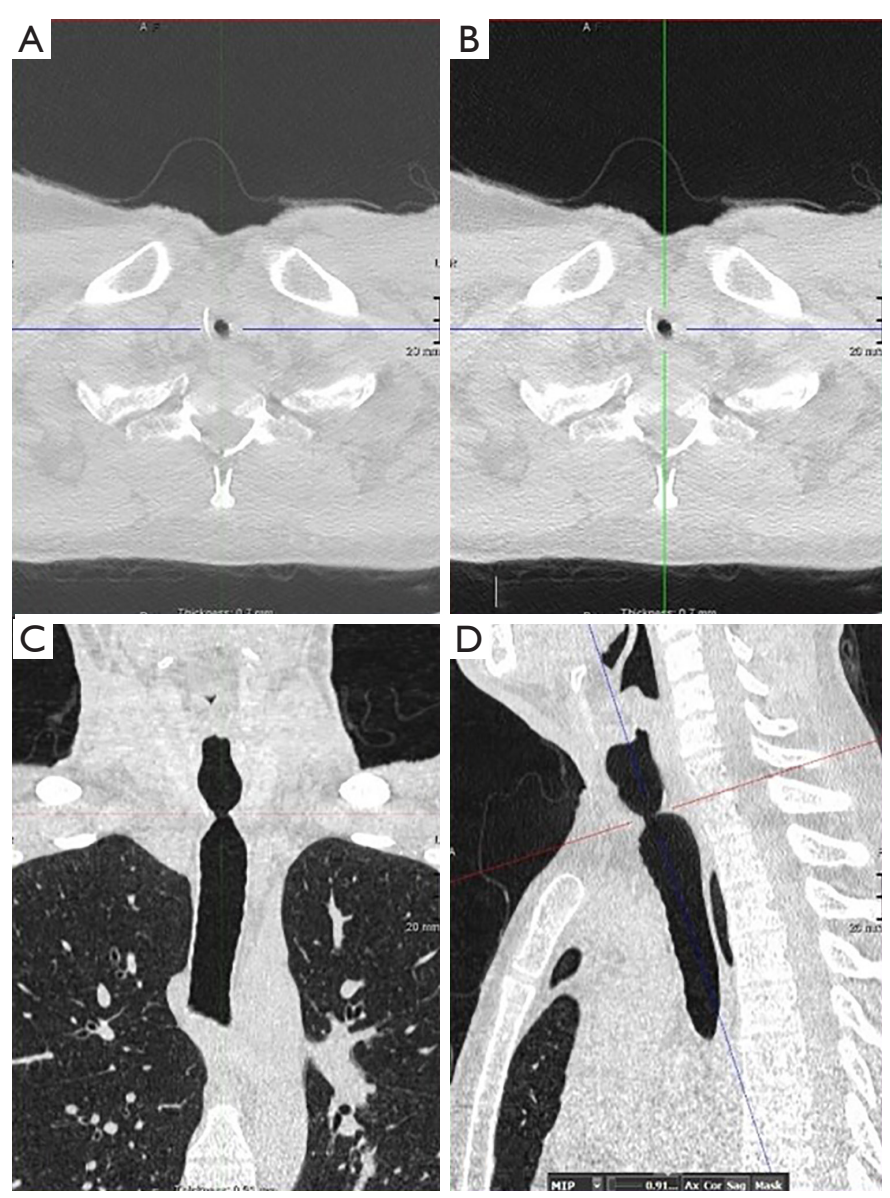

Figure 9 Axial (A,B), coronal (C) and sagittal (C) CT scan of the trachea depiction Subglottic Stenosis.

Table 2 Myer-Cotton classification system (43)

\begin{tabular}{ll}
\hline Classification & Obstruction \\
\hline Grade I & from 0 to $50 \%$ \\
Grade II & from $51 \%$ to $70 \%$ \\
Grade III & from $71 \%$ to $99 \%$ \\
Grade IV & No detectable lumen \\
\hline
\end{tabular}

It is likely to have fewer complications than a surgical approach as it preserves vocal cord function. However, it has the disadvantage of high recurrence rate, requiring repeated interventions $(39,40,45,46)$.

Historically, the treatment of iSGS has included dilatation of the involved segment using either boogies or barrels of rigid scopes of increasing diameter. This therapeutic approach may cause more trauma to the treatment site, leading to recurrence (47). The most
Table 3 McCaffrey system (2)

\begin{tabular}{ll}
\hline Stage & Characteristics \\
\hline 1 & $\begin{array}{l}\text { Lesion confined to the subglottis or trachea that are } \\
\text { less than } 1 \mathrm{~cm} \text { long }\end{array}$ \\
2 & $\begin{array}{l}\text { Subglottic lesion longer than } 1 \mathrm{~cm}, \text { within the cricoid } \\
\text { ring, not extending to the glottis or trachea }\end{array}$ \\
3 & $\begin{array}{l}\text { Subglottic lesion that extends into the upper trachea } \\
\text { but does not involve the glottis }\end{array}$ \\
4 & $\begin{array}{l}\text { Lesion involving the glottis with fixations or paralysis of } \\
\text { one or both vocal cords }\end{array}$ \\
\hline
\end{tabular}

common modern-day endoscopic procedure performed for simple iSGS is the "mucosal sparing technique", which is a relatively less invasive approach, involving radial incisions and gentle dilatation $(10,11,48)$. Either a laser beam (carbon dioxide, neodymium:yttrium aluminum garnet), an electrocautery knife or other methods may be used to place 

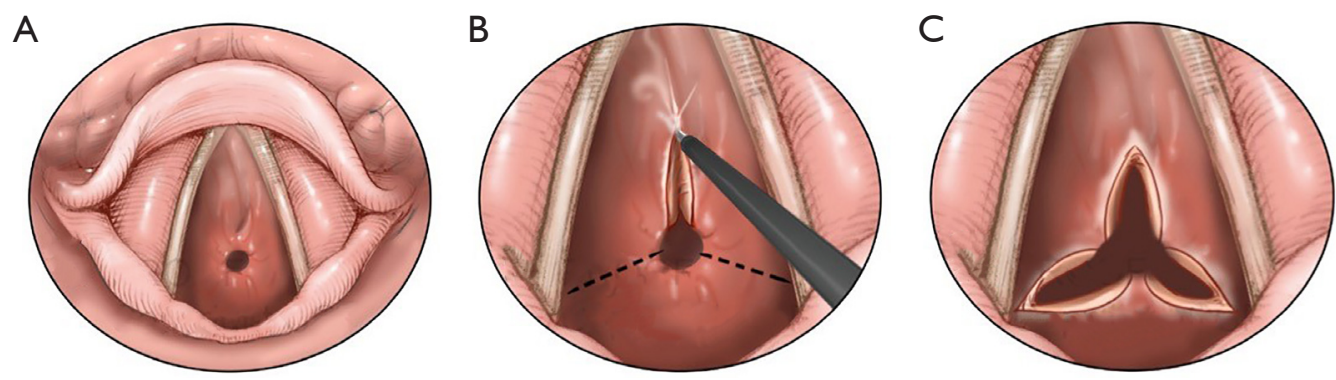

Figure 10 Radial incisions on the concentric scar.

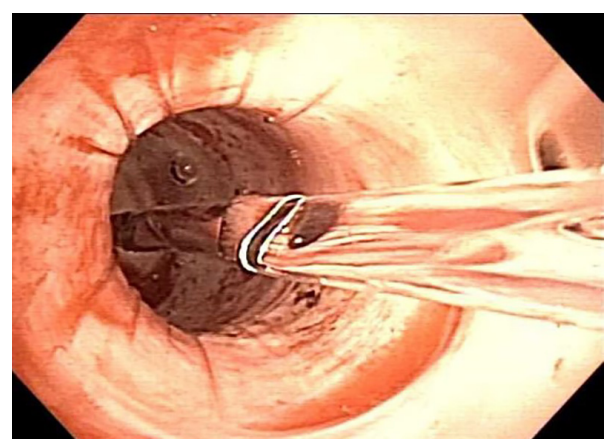

Figure 11 Gentle dilatation using a controlled radial expansion balloon.

radial incisions on the concentric scar, followed by a gentle dilatation using a balloon (11,48) (Figures 10-12). Complete mucosal ablation of the stenosis promotes recurrent scarring and poor long-term patency (10). Mucosal sparing techniques minimize airway trauma allowing organized tracheal mucosal restructuring and may serve as a platform for fostering normal re-epithelialization and airway repair.

Perotin et al. evaluated long-term outcomes after endoscopic management and reported initial success. However, this was followed by a recurrence rate of $30 \%$ at 6 months and $87 \%$ in 5 years (4). In carefully selected patients with a stenosis length of less than $1 \mathrm{~cm}$, endoscopic techniques, usually yield good results $(1,47)$. In a metaanalysis published by Yamamoto and coworkers in patients with a stenosis length of less than $1 \mathrm{~cm}$ without framework destruction, the success rate of an endoscopic approach was $79 \%$ (95\% CI, 69-88\%). However, in those with a mean stenosis length of greater than $1 \mathrm{~cm}$, the success rate was only $47 \%$ (49). The use of endoscopic procedures should be considered in individuals with complex stenosis to stabilize their airways before surgery or to palliate patients who are not suitable for surgery (50).

Mitomycin C-a cytotoxic agent isolated from Streptomyces

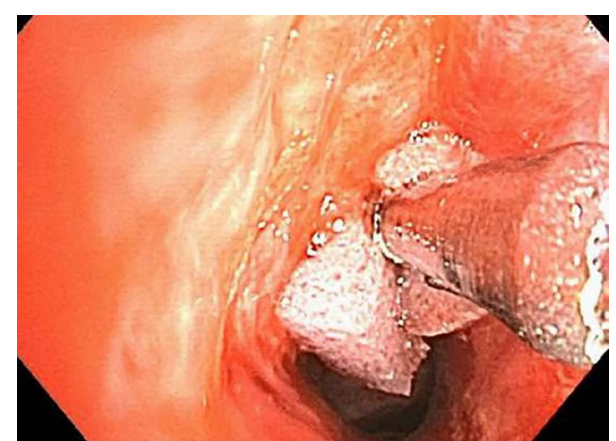

Figure 12 Mitomycin application.

caespitosus-inhibits DNA and RNA synthesis via various mechanisms. At lower doses, in cell cultures, it acts as an inhibitor of fibroblast proliferation $(51,52)$. Topical mitomycin has been used extensively in ophthalmology to prevent scarring and fibrosis following glaucoma procedures and pterygium surgeries (51). In an animal study, it has been demonstrated that a single application of low dose mitomycin reduces the occurrence of iatrogenic laryngotracheal stenosis (51). It has also been used with some success as an adjuvant treatment following mucosal sparing procedures, prolonging the interval to relapse (16,53-55). A review found that the usual application dose range between 0.1 to $10 \mathrm{mg} / \mathrm{mL}$ for 2 to 5 minutes (56). However, its use is still debatable due to the controversial evidence and the chance to produce complications (57-61). Subsequently, some experts discourage its utilization. Further studies are required to make an appropriate recommendation (16,51,52) (Figure 9).

Intralesional injection of steroids, although controversial, is widely used to decrease scar formation. It acts by delaying collagen synthesis in the early phases of the disease process and by increasing collagen lysis in the later phases of the scar formation, helping to avoid additional procedures, 
especially in subglottic stenosis related to autoimmune conditions $(62,63)$.

Stents are used in the management of airway obstruction caused by either tracheobronchial lesions or loss of structural integrity. Tracheobronchial stents are made of silicone, metallic wire mesh, or a combination of these materials (Hybrid). Hybrid stents are either partially or entirely covered with a variety of membranes, including silicone to prevent protrusion of granulation tissue through the wire mesh. Non-covered and partially covered metallic stents, either self-expanding or balloon expandable, are contraindicated in the management of iSGS due to the risk of excessive granulation tissue formation leading to worsening of airway obstruction (11). Although fully covered metallic stent seems to have less rate of complications in benign airway diseases than the metallic or the partially covered metallic stent, there is not enough experience related to its use for this indication (64).

Several investigators have used straight silicon stents in the management of iSGS with varying success. Silicon stents usually are placed either temporarily or on a permanent basis when endoscopic treatment has failed, and the patient is not a candidate for any surgical management $(10,65,66)$. The former strategy is intended to attenuate recurrence of airway obstruction beyond the size of the external diameter of the stent $(66,67)$. High risks of migration, malposition, infection and mucus plugging are significant limitations of this modality $(11,65)$.

The attempt at the external fixation of the stent is occasionally used in a patient with complex subglottic or upper tracheal stenosis. It has been recommended, preferably to a metal stent or in those patients who are not a candidate for surgery $(65,68)$. Although it has shown an improvement in symptoms (up to $100 \%$ ) and a low migration rate ( 0 to $22 \%$ ), it has never been popular due to having a difficult technique and a high rate of complication (55\% stent and $100 \%$ external fixation related in one series) $(65,68-71)$.

\section{Surgical management}

Understandable, patients presenting with severe and complex airway obstruction and impending respiratory failure are managed with a palliative tracheostomy (67).

Tracheostomy with silicone Montgomery T-tube placement is used to treat complex stenosis permanently in patients who are not good surgical candidates or as a bridge to surgery in patients who are temporarily at high risk to undergo a definitive operative resection of the stenotic area $(67,72)$.

Approximately $20 \%$ of patients with iSGS undergo an open surgery approach (40). The most definitive treatment is resection of laryngotracheal stenosis with primary anastomotic reconstruction with a T-tube. This approach has a high rate of success with a decannulation rate of over $95 \%(7,49,73)$. Age is the only variable correlated with unsuccessful airway patency (74).

Another technique with a high decannulation rate is laryngotracheal reconstruction without stenting, but this approach is associated with an increased rate of follow-up surgery and temporary tracheotomy. Laryngoplasty with or without graft has an overall success rate of $76 \%$ (49). Usually performed in long stenosis and glottic involvement, this method requires multiples surgeries to achieve the outcome. This procedure may potentially result in voice impairment to a lower pitch, which could be an issue of significant concern, especially to women $(49,73)$. These complex procedures are best performed in centers of excellence with a high volume of patients (40).

One of the authors of this review performs an innovative technique called "Maddern procedure" for isolated subglottic stenosis in a mature, non-inflammatory phase. Through an endoscopic approach (transoral), the stenosis is completely removed with the assistance of a soft-tissue shaver. The cricoid is then relined with either a buccal or skin graft, held in place for 2 weeks with a temporary silicone stent. This technique is minimally invasive, has the potential to preserve voice function completely, and may have a curative outcome. However, clinical trials are needed to evaluate this procedure.

\section{Conclusions}

In summary, iSGS is a rare fibrotic disease with a marked female predilection, the diagnosis of which is established by a thorough clinical and laboratory evaluation that aims to exclude other causes of subglottic stenosis. The respiratory symptoms are nonspecific and occur late in the course of the disease, requiring a high index of clinical suspicion. Endoscopic and surgical procedures remain the mainstay in the management of iSGS. However, aggressive medical treatment, including anti-reflux measures and inhaled corticosteroids, may play a role in reducing recurrences.

\section{Acknowledgments}

Funding: None. 


\section{Footnote}

Provenance and Peer Review: This article was commissioned by the Guest Editor (Kassem Harris) for the series "Interventional Pulmonology" published in Fournal of Thoracic Disease. The article was sent for external peer review organized by the Guest Editor and the editorial office.

Conflicts of Interest: The series "Interventional Pulmonology" was commissioned by the editorial office without any funding or sponsorship. The authors have no other conflicts of interest to declare.

Open Access Statement: This is an Open Access article distributed in accordance with the Creative Commons Attribution-NonCommercial-NoDerivs 4.0 International License (CC BY-NC-ND 4.0), which permits the noncommercial replication and distribution of the article with the strict proviso that no changes or edits are made and the original work is properly cited (including links to both the formal publication through the relevant DOI and the license). See: https://creativecommons.org/licenses/by-nc-nd/4.0/.

\section{References}

1. Valdez TA, Shapshay SM. Idiopathic subglottic stenosis revisited. Ann Otol Rhinol Laryngol 2002;111:690-5.

2. McCaffrey T V. Classification of laryngotracheal stenosis. Laryngoscope 1992;102:1335-40.

3. Maldonado F, Loiselle A, Depew ZS, et al. Idiopathic subglottic stenosis: An evolving therapeutic algorithm. Laryngoscope 2014;124:498-503.

4. Perotin J-MM, Jeanfaivre T, Thibout Y, et al. Endoscopic management of idiopathic tracheal stenosis. Ann Thorac Surg 2011;92:297-301.

5. Ashiku SK, Mathisen DJ. Idiopathic laryngotracheal stenosis. Chest Surg Clin N Am 2003;13:257-69.

6. Brandenburg JH. Idiopathic subglottic stenosis. Trans Am Acad Ophthalmol Otolaryngol 1972;76:1402-6.

7. Ashiku SK, Kuzucu A, Grillo HC, et al. Idiopathic laryngotracheal stenosis: Effective definitive treatment with laryngotracheal resection. J Thorac Cardiovasc Surg 2004;127:99-107.

8. Puchalski J, Musani AI. Tracheobronchial Stenosis. Causes and Advances in Management. Clin Chest Med 2013;34:557-67.

9. Maldonado F, Tomassetti S, Ryu JH. Orphan
Tracheopathies. In: Cottin V, Cordier JF, Richeldi L, editors. Orphan Lung Diseases. London: Springer London, 73-89.

10. Mehta AC, Harris RJ, De Boer GE. Endoscopic management of benign airway stenosis. Clin Chest Med 1995;16:401-13.

11. Shapshay SM, Valdez TA. Bronchoscopic management of benign stenosis. Chest Surg Clin N Am 2001;11:749-68.

12. Blumin JH, Johnston N. Evidence of extraesophageal reflux in idiopathic subglottic stenosis. Laryngoscope 2011;121:1266-73.

13. Langford CA, Sneller MC, Hallahan CW, et al. Clinical features and therapeutic management of subglottic stenosis in patients with Wegener's granulomatosis. Arthritis Rheum 1996;39:1754-60.

14. Lebovics RS, Hoffman GS, Leavitt RY, et al. The management of subglottic stenosis in patients with Wegener's granulomatosis. Laryngoscope 1992;102:1341-5.

15. Daum TE, Specks U, Colby TV, et al. Tracheobronchial involvement in Wegener's granulomatosis. Am J Respir Crit Care Med 1995;151:522-6.

16. Feinstein AJ, Goel A, Raghavan G, et al. Endoscopic management of subglottic stenosis. JAMA Otolaryngol Head Neck Surg 2017;143:500-5.

17. Kupeli E, Mehta AC. Late endobronchial Wegener's granulomatosis. J Bronchol 2002;9:125-6.

18. Alaani A, Hogg RP, Lee ABD. Wegener's granulomatosis and subglottic stenosis: Management of the airway. J Laryngol Otol 2004;118:786-90.

19. Devaney K, Travis W, Hoffman G, et al. Interpretation of Head and Neck Biopsies in Wegener's Granulomatosis. Am J Surg Pathol 1990;14:555-64.

20. Gluth MB, Shinners P a, Kasperbauer JL. Subglottic stenosis associated with Wegener's granulomatosis. Laryngoscope 2003;113:1304-7.

21. Taylor SC, Clayburgh DR, Rosenbaum JT, et al. Clinical Manifestations and Treatment of Idiopathic and Wegener Granulomatosis-Associated Subglottic Stenosis. JAMA Otolaryngol Head Neck Surg 2013;139:76.

22. Statement on sarcoidosis. Joint Statement of the American Thoracic Society (ATS), the European Respiratory Society (ERS) and the World Association of Sarcoidosis and Other Granulomatous Disorders (WASOG) adopted by the ATS Board of Directors and by the ER. Am J Respir Crit Care Med 1999;160:736-55.

23. Polychronopoulos VS, Prakash UBS. Airway involvement in sarcoidosis. Chest 2009;136:1371-80.

24. Viskum K, Vestbo J. Vital prognosis in intrathoracic 
sarcoidosis with special reference to pulmonary function and radiological stage. Eur Respir J 1993;6:349-53.

25. Djalilian M, Mcdonald TJ, Devine KD, et al.

Nontraumatic, nonneoplastic subglottic stenosis. Ann Otol Rhinol Laryngol 1975;84:757-63.

26. Camus P, Colby T V. The lung in inflammatory bowel disease. Eur Respir J 2000;15:5-10.

27. Hoffmann RM, Kruis W. Rare Extraintestinal Manifestations of Inflammatory Bowel Disease. Inflamm Bowel Dis 2004;10:140-7.

28. Cohen M, Sahn SA. Bronchiectasis in Systemic Diseases. Chest 1999;116:1063-74.

29. Saad CP, Budev MM, Farver C, et al. Crohn's disease and severe tracheobronchial stenosis. J Bronchol 2003;10:43-7.

30. Ramaswamy A, Panchabhai TS, Farver C, et al. Recurrent tracheal stenosis: A novel presentation of silicosis. Ann Am Thorac Soc 2016;13:1184-7.

31. Lee P, Culver DA, Farver C, et al. Syndrome of iron pill aspiration. Chest 2002;121:1355-7.

32. Kupeli E, Khemasuwan D, Tunsupon P, et al. 'Pills' and the air passages: A continuum. Chest 2015;147:242-50.

33. Manickavasagam J, Yapa S, Bateman ND, et al. Congenital familial subglottic stenosis: A case series and review of literature. Int J Pediatr Otorhinolaryngol 2014;78:359-62.

34. Dumoulin E, Stather DR, Gelfand G, et al. Idiopathic subglottic stenosis: A familial predisposition. Ann Thorac Surg 2013;95:1084-6.

35. Rahman NA, Fruchter O, Shitrit D, et al. Flexible bronchoscopic management of benign tracheal stenosis: Long term follow-up of 115 patients. J Cardiothorac Surg 2010;5:2.

36. Couraud L, Jougon JB, Velly JF. Surgical treatment of nontumoral stenoses of the upper airway. Ann Thorac Surg 1995;60:250-9.

37. Damrose EJ. On the development of idiopathic subglottic stenosis. Med Hypotheses 2008;71:122-5.

38. Costantino CL, Mathisen DJ. Idiopathic laryngotracheal stenosis. J Thorac Dis 2016;8:S204-9.

39. Grillo HC, Mark EJ, Mathisen DJ, et al. Idiopathic laryngotracheal stenosis and its management. Ann Thorac Surg 1993;56:80-7.

40. Gelbard A, Donovan DT, Ongkasuwan J, et al. Disease homogeneity and treatment heterogeneity in idiopathic subglottic stenosis. Laryngoscope 2016;126:1390-6.

41. Elizur A, Goldberg MR, Disin A, et al. A 14-year-old female with fixed airflow obstruction. Am J Respir Crit Care Med 2013;188:1365.

42. Morshed K, Trojanowska A, Szymański M, et al.
Evaluation of tracheal stenosis: Comparison between computed tomography virtual tracheobronchoscopy with multiplanar reformatting, flexible tracheofiberoscopy and intra-operative findings. Eur Arch Otorhinolaryngol 2011;268:591-7.

43. Myer CM, O'connor DM, Cotton RT. Proposed grading system for subglottic stenosis based on endotracheal tube sizes. Ann Otol Rhinol Laryngol 1994;103:319-23.

44. Colt H, Colt H. Bronchoscopy and Central Airway Disorders: A Patient-Centered Approach. Available online: http://www.clinicalkey.com/dura/browse/bookChapter/3s2.0-C20100650541

45. Smith ME, Roy N, Stoddard K, et al. How does cricotracheal resection affect the female voice? Ann Otol Rhinol Laryngol 2008;117:85-9.

46. Nouraei SA, Sandhu GS. Outcome of a multimodality approach to the management of idiopathic subglottic stenosis. Laryngoscope 2013;123:2474-84.

47. Mehta AC, Lee FYW, Cordasco EM, et al. Concentric tracheal and subglottic stenosis: Management using the Nd-YAG laser for mucosal sparing followed by gentle dilatation. Chest 1993;104:673-7.

48. Tremblay A, Coulter TD, Mehta AC. Modification of a Mucosal-Sparing Technique Using Electrocautery and Balloon Dilatation in the Endoscopic Management of Web-Like Benign Airway Stenosis. J Bronchol 2003;10:268-71.

49. Yamamoto K, Kojima F, Tomiyama K, et al. Meta-Analysis of Therapeutic Procedures forAcquired Subglottic Stenosis in Adults. Ann Thorac Surg 2011;91:1747-53.

50. D'Andrilli A, Venuta F, Rendina EA, et al. Subglottic tracheal stenosis. J Thorac Dis 2016;8:S140-7.

51. Eliashar R, Eliachar I, Esclamado R, et al. Mitomycin prevent laryngotracheal stenosis? Laryngoscope 1999;109:1594-600.

52. Penafiel A, Lee P, Hsu A, et al. Topical Mitomycin-C for Obstructing Endobronchial Granuloma. Ann Thorac Surg 2006;82:e22-3.

53. Smith ME, Elstad M. Mitomycin c and the Endoscopic treatment of laryngotracheal stenosis: Are two applications better than one? Laryngoscope 2009;119:272-83.

54. Perepelitsyn I, Shapshay SM. Endoscopic treatment of laryngeal and tracheal stenosis - Has mitomycin C improved the outcome? Otolaryngol Head Neck Surg 2004;131:16-20.

55. Roediger FC, Orloff LA, Courey MS. Adult subglottic stenosis: Management with laser incisions and mitomycin-C. Laryngoscope 2008;118:1542-6. 
56. Whited CW, Dailey SH. Is mitomycin C useful as an adjuvant therapy in endoscopic treatment of laryngotracheal stenosis? Laryngoscope 2015;125:2243-4.

57. Rea F, Callegaro D, Loy M, et al. Benign tracheal and laryngotracheal stenosis: Surgical treatment and results. Eur J Cardiothorac Surg 2002;22:352-6.

58. Roh JL, Kim DH, Rha KS, et al. Benefits and risks of mitomycin use in the traumatized tracheal mucosa. Otolaryngol Head Neck Surg 2007;136:459-63.

59. Agrawal N, Morrison GA. Laryngeal cancer after topical mitomycin $\mathrm{C}$ application. J Laryngol Otol 2006;120:1075-6.

60. Eliashar R, Gross M, Maly B, et al. Mitomycin Does Not Prevent Laryngotracheal Repeat Stenosis after Endoscopic Dilation Surgery: An Animal Study. Laryngoscope 2004;114:743-6.

61. Hartnick CJ, Hartley BE, Lacy PD, et al. Topical mitomycin application after laryngotracheal reconstruction: a randomized, double-blind, placebocontrolled trial. Arch Otolaryngol Head Neck Surg 2001;127:1260-4.

62. Hirshoren N, Eliashar R. Wound-healing modulation in upper airway stenosis-myths and facts. Head Neck 2009;31:111-26.

63. Wierzbicka M, Tokarski M, Puszczewicz M, et al. The efficacy of submucosal corticosteroid injection and dilatation in subglottic stenosis of different aetiology. J Laryngol Otol 2016;130:674-9.

64. Fortin M, Lacasse Y, Elharrar X, et al. Safety and Efficacy of a Fully Covered Self-Expandable Metallic Stent in Benign Airway Stenosis. Respiration 2017;93:430-5.

65. Colt HG, Harrell J, Neuman TR, et al. External fixation

Cite this article as: Aravena C, Almeida FA, Mukhopadhyay S, Ghosh S, Lorenz RR, Murthy SC, Mehta AC. Idiopathic subglottic stenosis: a review. J Thorac Dis 2020;12(3):1100-1111. doi: $10.21037 /$ jtd.2019.11.43 of subglottic tracheal stents. Chest 1994;105:1653-7.

66. Dumon JF. A dedicated tracheobronchial stent. Chest 1990;97:328-32.

67. Montgomery WW. T-Tube Tracheal Stent. Arch Otolaryngol 1965;82:320-1.

68. Majid A, Fernandez-Bussy S, Kent M, et al. External fixation of proximal tracheal airway stents: A modified technique. Ann Thorac Surg 2012;93:e167-9.

69. Huang J, Zhang Z, Zhang T. Suture fixation of tracheal stents for the treatment of upper trachea stenosis: A retrospective study. J Cardiothorac Surg 2018;13:111-6.

70. Miwa K, Takamori S, Hayashi A, et al. Fixation of silicone stents in the subglottic trachea: Preventing stent migration using a fixation apparatus. Ann Thorac Surg 2004;78:2188-90.

71. Musani AI, Jensen K, Mitchell JD, et al. Novel use of a percutaneous endoscopic gastrostomy tube fastener for securing silicone tracheal stents in patients with benign proximal airway obstruction. J Bronchology Interv Pulmonol 2012;19:121-5.

72. Gaissert HA, Grillo HC, Mathisen DJ, et al. Temporary and permanent restoration of airway continuity with the tracheal T-tube. J Thorac Cardiovasc Surg 1994;107:600-6.

73. Lorenz RR. Adult laryngotracheal stenosis: Etiology and surgical management. Curr Opin Otolaryngol Head Neck Surg 2003;11:467-72.

74. Wolf M, Shapira Y, Talmi YP, et al. Laryngotracheal Anastomosis: Primary and Revised Procedures. Available online: https://onlinelibrary-wiley-com.ccmain.ohionet. org/doi/pdf/10.1097/00005537-200104000-00012. (2001, accessed 3 June 2019). 